\title{
Relationship Between the Personality Type and Work Life Balance Among Academic Staff of University of Kelaniya
}

\author{
Padmasiri M.K.D ${ }^{1}$ and Mahalaekamge W.G.S ${ }^{2}$ \\ ${ }^{1}$ Department of Human Resource Management, \\ University of Kelaniya, Sri Lanka. \\ padmasirimkd@gmail.com \\ ${ }^{2}$ Department of Human Resource Management, \\ University of Kelaniya, Sri Lanka. \\ geethanimahalekamge@yahoo.com
}

\begin{abstract}
Abstrat
The focus of this research is to find out the impact of different types of personality and Work Life Balance (WLB) of academic staff of University of Kelaniya. Researchers used standardized personality assessment named as Myers-Briggs Type Indicator (MBTI) to assess the type of personality. Objectives are, to examine the impact of personality type of academic staff in University of Kelaniya on their $W L B$, to identify the level and type of personality of academic staff, to identify the level of WLB of academic staff and to recommend suitable personality type for WLB.
\end{abstract}

Research sample consisted with 180 lecturers out of 560 University of Kelaniya. Standardized questionnaire used to collect data. Collected 
data analyzed and evaluated manually as well as using the SPSS and Excel. By considering the nature of the study conducted an Anova test.

According to MBTI there are 16 personality types where one personality consists with 4 indicators. Indicators are as follow, IIntroversion, E-Extraversion, S- Sensing, I- Intuition, T- Thinking, FFeeling, J-Judging, P-Perception. In sample ISFJ, ISTJ, ESFJ and ENFJ each personality type have 4 indicators, ISFP, INTP, ESTJ and ENTJ each personality type has 3 indicators, INFJ has 2 indicators and INTJ, ISTP, ESTP, ENFP and ENTP each personality has only 1 indicator. According to the findings ISTP, ISFP, INTP, ESTP, ESFP, ISTJ, ENFP, ENTP, ESTJ, ESFJ, ENFJ, ENTJ personality have work life balance but people who have ISFJ, INFJ, INTJ, INFP personality have moderately balanced work life. There are no WL imbalance respondents. Sample consisted with 133 females \& 47 males. Mean value of females and males are 36.57 and 34.44 .

Researcher recommended to enhance Extraversion, Intuition and Feeling indicators to execute the responders' teacher career effectively. And suggested to enhance ENTP which emphasized Visionary career and its well match with the teacher career. Finally recommended to INTJ personality responders to attempt to change $N$ indicator to become $S$ by enhancing sensing abilities to balance WL. Further research areas are find WLB of academic staff with each personality type but respond to gender differentiation, marital status differences.

Keywords: MBTI, Personality, Work life balance 


\section{Introduction}

This study conducted for the academic staff of the state University. Work life of academic staff rather different from the other careers due to special characteristics relate to this field such as knowledge base work, high work load. According to Rutter, Hezberg and Paice (2002) identified several characteristics among the academic staff. High selfexpectation, role overload, conflicting job demands. Therefore the current study focuses on the testing the relationship of level of personality on WLB of academic staff in University of Kelaniya.

Human Resource Management (HRM) is an about the effective and efficient utilization of workforce in order to achieve an organizations' goals and objectives. The generic purpose of HRM is to generate and retain the most appropriate and contented work force within the organization. Human resourcing is the key to determining organizational success. Balancing work - family is a vital factor to the employee for their personal as well as career development. A healthy practice of WLB is affected by the individual differences such as different personalities. Hence individually employee has to balance their work family.

\section{Research problem}

WL 'imbalance' is a big concern in this century because of increasing problems related to employee health, monotony at work place, 
declining levels of productivity and efficiency at the employee level. The imbalance also has a negative relationship in the personal life of working people, some of which have even become social hazardsincreasing number of divorces, infertility due high stress levels, advent of nuclear families, etc.(Devadoss A.V, 2013). So an individual should be able to keep a proper balance between work and life, there are many factors which are influencing the work life balance, and however an individual's personality also plays a vital role in balancing the work life and different personality types relationship to work life balance of employees. It is easy to be realized that the Personality of an individual can have effects on his/her own balance between work and life. (Devadoss A.V, 2013). Consequently, identified problem is "How personality type of academic staff in University of Kelaniya relationships on their WLB?"

\section{Research objectives}

General objective of this research is to examine the relationship of personality type of academic staff in University of Kelaniya on their WLB. Specific objectives are,

1. To identify the level and type of personality of academic staff in University of Kelaniya.

2. To identify the level of WLB of academic staff in University of Kelaniya.

3. To recommend suitable personality type for WLB. 


\section{Hypotheses}

H0: There is no relationship of personality type on WLB.

H1: There is a relationship of personality type on WLB.

\section{Literature Review}

\subsection{Personality}

Personality is the set of psychological traits and mechanisms within the individual that are organized and relatively stable and that influence his or her interactions with, and adaptations to, the physical, and social environments. And also Personality refers to a set of unique personal characteristics, including motives, emotions, values, interests, attitudes, and competencies (Argyris C. , 2008).

D. Guest, 2003 defined the personality as the extent to which family or work is a central life interest influences the perceptions of balance of every individual. "Personality is the entire mental organization of a human being at any stage of his development. It holds every phase of human character: intellect, temperament, skill, morality and every attitude that has been built up in the course of one's life". (Devadoss A.V, 2013). MBTI is the test which is used to measure the human personality type. 16 types of personality were pertained to MBTI (Briggs, 1980, 1995). 
Different personality tests are existed to measure the personality of human. Among various type measurements this research emphasize about the Myers-Briggs Type Indicator (MBTI). MBTI assessment is a psychometric questionnaire designed to measure psychological preferences in how people perceive the world and make decisions (Myers, 1980, 1995). The MBTI is constructed for normal populations and emphasizes the value of naturally occurring differences (Pearman \& Albritton, 1997). In MBTI 16 types of personality are typically referred to by an abbreviation of four letters - the initial letters of each of their four type preferences (except in the case of intuition, which uses the abbreviation $\mathrm{N}$ to distinguish it from introversion). For instance: ESTJ: extraversion (E), sensing (S), thinking (T), judgment $(\mathrm{J})$, INFP: introversion $(\mathrm{I})$, intuition $(\mathrm{N})$, feeling $(\mathrm{F})$, perception $(\mathrm{P})$. This method of abbreviation is applied to all 16 types.

\section{Figure 1: Personality Types}

\begin{tabular}{|l|l|l|l|}
\hline ISTJ & ISFJ & INFJ & INTJ \\
\hline ISTP & ISFP & INFP & INTP \\
\hline ESTP & ESFP & ENFP & ENTP \\
\hline ESTJ & ESFJ & ENFJ & ENTJ \\
\hline
\end{tabular}

(Jung, 1971) 
Kelaniya Journal of Human Resource Management

Volume 8 Number 1 January 2013

\subsection{Extraversion/Introversion (E/I)}

Myers-Briggs literature uses the terms extraversion and introversion. Extraversion means "outward-turning" and introversion means "inward-turning" (Zeisset, 2006). The extravert's flow is directed outward toward people and objects, and the introvert's is directed inward toward concepts and ideas. Contrasting characteristics between extraverts and introverts include the following: Extraverts are "action" oriented, while introverts are "thought" oriented, Extraverts seek "breadth" of knowledge and influence, while introverts seek "depth" of knowledge and influence, Extraverts often prefer more "frequent" interaction, while introverts prefer more "substantial" interaction, Extraverts recharge and get their energy from spending time with people, while introverts recharge and get their energy from spending time alone; they consume their energy through the opposite process. (Tieger \& Barron-Tieger).

\subsection{Sensing/ Intuition $(S / N)$}

Sensing and intuition are the information-gathering (perceiving) functions. They describe how new information is understood and interpreted. Individuals who prefer sensing are more likely to trust information that is in the present, tangible, and concrete: that is, information that can be understood by the five senses. On the other hand, those who prefer intuition tend to trust information that is more 
abstract or theoretical, that can be associated with other information (either remembered or discovered by seeking a wider context or pattern).

\subsection{Thinking/ Feeling (T/F)}

Thinking and feeling are the decision-making (judging) functions. Those who prefer thinking tend to decide things from a more detached standpoint, measuring the decision by what seems reasonable, logical, causal, consistent, and matching a given set of rules. Those who prefer feeling tend to come to decisions by associating or empathizing with the situation, looking at it 'from the inside' and weighing the situation to achieve, on balance, the greatest harmony, consensus and fit, considering the needs of the people involved.

\subsection{Judging/ Perception (J/P)}

Myers and Briggs held that types with a preference for judging show the world their preferred thinking or feeling. So TJ types tend to appear to the world as logical, and FJ types as empathetic. Those types who prefer perception show the world their sensing or intuition. So SP types tend to appear to the world as concrete and NP types as abstract. MBTI personality test was developed with combination of aforementioned each personality type. And ultimately found 16 types of personalities. 
Figure 2: 16 types of personality

\begin{tabular}{|c|c|c|c|c|}
\hline & FJ & FP & $\mathrm{TJ}$ & TP \\
\hline EN & & & & \\
\hline ES & & & & \\
\hline IN & & & & \\
\hline IS & & & & \\
\hline
\end{tabular}

\subsection{WLB}

Work Life Balance, in its broadest sense, is defined as a satisfactory level of involvement or 'fit' between the multiple roles in a person's life (Hudson, 2005). WLB is about people having measure of their control over when, where and how they work. (Devadoss A.V, 2013)

According to (Susi, 2001), WLB is "primarily a matter of deciding when to holdon and when to let go. According to (Clark, 2003), the very term, WLB refers to satisfaction and good functioning at work and at home with a minimum of role conflict. In the words of (Blatt, 2002) WLB has been characterized by the absence of unacceptable levels of conflict between work and non-work demands.

The Blueprint for Life-Work Designs (Haché. L, 2002) described a complex inter-relationship of life roles. An assortment of "balance wheels" are widely available, typically including such aspects of life as social (e.g., family, friends, and romantic relationships), physical 
(e.g., physical fitness, environmental conditions, and general health), intellectual (e.g., education, mental challenge), emotional, spiritual, and work (including career, money, homemaking, and community service). For the purposes of this paper, work-life balance will be uniquely defined by individuals, taking into account any or all of the aspects above.

Sub dimensions of WLB are, work, family, self and social. It developed according to Dundas, (2008) he described WLB is about effectively managing the juggling act between paid work and all other activities that are important to people such as family, community activities, social, personal development (self) and leisure and recreation. Working definition of WLB is a the way of managing time among juggling demands such as work, family, social and spiritual activities of a personal life.

\subsection{Personality influence on WLB}

An individual should be able to keep a proper balance between work and life, there are many factors which are influencing the work life balance, however and individual's personality also plays a vital role in balancing the work life. The approach of psychology of individual differences may be also fruitful for research of enhance our understanding of perceptions of work life balance. It is easy to be realized that the personality of an individual can have effects on his/her own balance between work and family (Devadoss A.V, 2013) 
Kelaniya Journal of Human Resource Management

Volume 8 Number 1 January 2013

\section{Research Methodology}

\subsection{Conceptual Framework}

Figure 2: Conceptualization of MBTI and WLB

\begin{tabular}{|l|}
\hline MBTI personal \\
\hline ISTJ \\
\hline ISFJ \\
\hline INFJ \\
\hline INTJ \\
\hline ISTP \\
\hline ISFP \\
\hline INFP \\
\hline ESTP \\
\hline INTP \\
\hline ESFP \\
\hline ENFP \\
\hline \hline ENTP \\
\hline ESTJ \\
\hline ESFJ \\
\hline ENFJ \\
\hline ENTJ \\
\hline
\end{tabular}

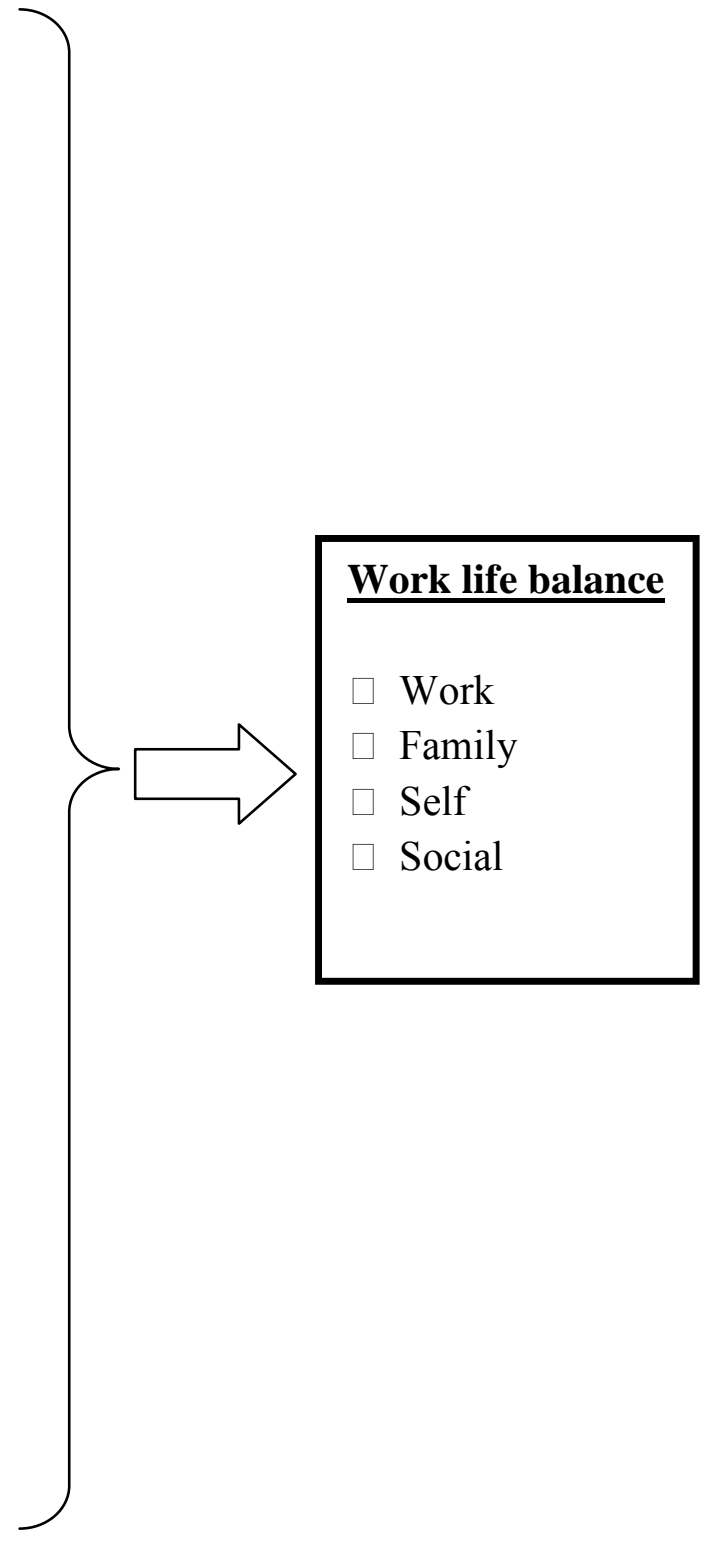




\subsection{Sampling Method}

Sampling is the process of selecting a sufficient number of elements from the population (Sekaran, 2006). This research used simple random sampling which means each member of the population has an equal chance of being in the sample. Here the sample consists of 150 lecturers from the 560 academic staff of University of Kelaniya.

\subsection{Method of Data collection}

Questionnaire is a pre-formulated written set of questions to which respondents record their answers, usually within rather closely defined alternatives (Sekaran, 2006). The questionnaire consists 45 close ended questions with three parts; personal information, WLB and personality. For the purpose the researcher used two standard questionnaires and one is to identify the WLB (Minnesota satisfaction questionnaire and Zarca interactive questionnaire) which consists with 10 questions. To measure the dimensions of WLB used questions numbers are as follow in (part B mentioned measurement of WLB).

\section{Table 1: Structure of the Questionnaire}

\begin{tabular}{|l|l|l|}
\hline Dimensions & Indicators Question No \\
\hline Work & $\begin{array}{l}\text { Different working arrangements } \\
\text { and working hours }\end{array}$ & 1,2 \\
\cline { 2 - 3 } & Company policies and practices & 10 \\
\cline { 2 - 3 } & $\begin{array}{l}\text { Management and colleague } \\
\text { support }\end{array}$ & $4,5,6$ \\
\hline Family & Family commitment & 8,9 \\
\hline Social & Relationship with friends & 7 \\
\hline Self & Spiritual & 3 \\
\hline
\end{tabular}


Kelaniya Journal of Human Resource Management

Volume 8 Number 1 January 2013

The other questionnaire (jungian16-type personality assessment) is to identify the type of personality which consists with 28 questions. And to measure each type of indicators of personality used separate questions as following figure. And based on the data collected desired the responders' personality and it was predicted by taking highest markings indicator from the couple of indicators' values. For an instance for I marked for 6 times $\mathrm{E}$ marked for 2 times, then considered responder has I personality due to highest marked.

Figure 3: MBTI measurement

\begin{tabular}{|c|c|c|c|c|c|c|c|}
\hline Score for I & Score for $E$ & Score for $\mathbf{S}$ & Score for $\mathbf{N}$ & Score for $\mathbf{T}$ & Score for $F$ & Score for $\mathbf{J}$ & Score for $P$ \\
\hline $2 a$ & $2 \mathrm{~b}$ & $1 \mathrm{~b}$ & $1 a$ & $3 a$ & $3 \mathrm{~b}$ & $4 a$ & $4 \mathrm{~b}$ \\
\hline $6 a$ & $6 \mathrm{~b}$ & $10 \mathrm{~b}$ & $10 a$ & $5 a$ & $5 b$ & $7 a$ & $7 \mathrm{~b}$ \\
\hline $11 a$ & $11 b$ & $13 a$ & $13 \mathrm{~b}$ & $12 a$ & $12 \mathrm{~b}$ & $8 b$ & $8 a$ \\
\hline $15 b$ & $15 \mathrm{a}$ & $16 a$ & $16 \mathrm{~b}$ & $14 \mathrm{~b}$ & $14 a$ & $9 \mathrm{a}$ & $9 \mathrm{~b}$ \\
\hline $19 b$ & $19 \mathrm{a}$ & $17 a$ & $17 \mathrm{~b}$ & $20 \mathrm{a}$ & $20 \mathrm{~b}$ & $18 \mathrm{~b}$ & $18 a$ \\
\hline $22 a$ & $22 b$ & $21 a$ & $21 b$ & $24 b$ & $24 a$ & $23 \mathrm{~b}$ & $23 a$ \\
\hline $27 \mathrm{~b}$ & $27 a$ & $28 b$ & $28 a$ & $25 a$ & $25 b$ & $26 a$ & $26 b$ \\
\hline 326 & $32 a$ & $30 \mathrm{~b}$ & $30 a$ & $29 \mathrm{~b}$ & $29 a$ & $31 a$ & $31 b$ \\
\hline \multicolumn{2}{|c|}{$\begin{array}{l}\text { Identify the one with the } \\
\text { more points : I or } E\end{array}$} & \multicolumn{2}{|c|}{$\begin{array}{l}\text { Identify the one with the } \\
\text { more points: } \mathrm{S} \text { or } \mathrm{N}\end{array}$} & \multicolumn{2}{|c|}{$\begin{array}{l}\text { dentify the one with the } \\
\text { more points: } T \text { or } F\end{array}$} & \multicolumn{2}{|c|}{$\begin{array}{l}\text { Identify the one with the } \\
\text { more points : J or } P\end{array}$} \\
\hline
\end{tabular}




\section{Data analysis}

Quantitative method was used to analyze the data. The data analyzed in this study based on the questionnaires. Under the quantitative method, the Likert Scale was included to measure WLB. Likert- scales were used to score the responses as strongly agree (1) Agree (2) Neither Agree nor Disagree (3) Disagree (4) and strongly disagree (5). And to find the type of personality used given analyze method by the jungian16-type personality assessment. The data collected and measured by the use of questionnaires are analyzed and evaluated manually as well as using the SPSS and Excel. By considering the nature of the study conducted an Independent sample t test. There are 8 indicators in MBTI and each indicator got following response from responders.

Table 2: Frequency of personality indicators

\begin{tabular}{|l|l|}
\hline Indicator & Frequency \\
\hline I & 75 \\
\hline E & 75 \\
\hline S & 80 \\
\hline N & 70 \\
\hline T & 75 \\
\hline F & 65 \\
\hline J & 95 \\
\hline P & 45 \\
\hline
\end{tabular}

According to table 2 most people have Judging personality indicator and least people have Perception personality indicator. Sample of the 
Kelaniya Journal of Human Resource Management

Volume 8 Number 1 January 2013

study is knowledge workers therefore judging personality important to academics staff to carry out their profession successfully. According to the Perception indicator's characteristics includes try to see the world on sensing and intuition (Myers, 1980, 1995). Hence findings showed that research sample improved their knowledge by learning than intuition. Therefore most of the academic staff has Judging indicator in their personality than Perception indicator.

According to MBTI there are sixteen (16) types of personalities. Based on findings frequency of those personalities are:

Table 3: Frequency of personality types

\begin{tabular}{|l|l|l|}
\hline Personality type & Frequency & Average \\
\hline ISFJ & 10 & 0.10 \\
\hline INFJ & 10 & 0.10 \\
\hline INTJ & 5 & 0.05 \\
\hline ISTP & 5 & 0.05 \\
\hline ISFP & 10 & 0.10 \\
\hline INFP & 5 & 0.05 \\
\hline INTP & 15 & 0.15 \\
\hline ESTP & 5 & 0.05 \\
\hline ESFP & 5 & 0.05 \\
\hline ISTJ & 15 & 0.15 \\
\hline ENFP & 5 & 0.05 \\
\hline ENTP & 5 & 0.05 \\
\hline ESTJ & 15 & 0.15 \\
\hline ESFJ & 15 & 0.15 \\
\hline ENFJ & 15 & 0.15 \\
\hline ENTJ & 10 & 0.10 \\
\hline
\end{tabular}




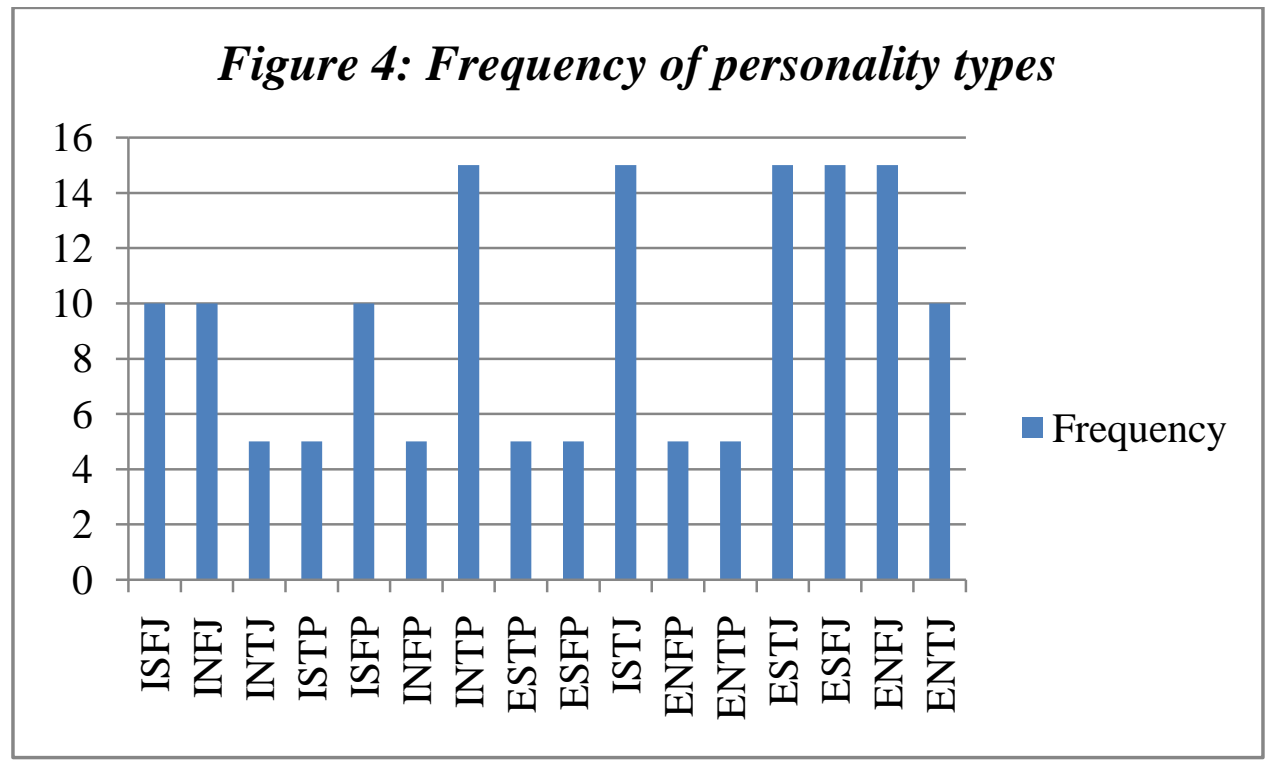

According to the above table and figure for the personality type of INTP, ISTJ, ESTJ, ESF, ENFJ the frequency is 15 in each. But for the personality type of INTJ, ISTP, ESTP, ESFP, ENFP and ENTP has low frequency of 5 in each.

\subsection{WLB Average (WLBA)}

Table 4: Work Life Balance Average

\begin{tabular}{|l|l|}
\hline Personality Type & Work Life Balance Average \\
\hline ISFJ & 0.43 \\
\hline INFJ & 0.44 \\
\hline INTJ & 0.38 \\
\hline ISTP & 0.58 \\
\hline
\end{tabular}




\begin{tabular}{|l|l|}
\hline ISFP & 0.62 \\
\hline INFP & 0.44 \\
\hline INTP & 0.67 \\
\hline ESTP & 0.60 \\
\hline ESFP & 0.80 \\
\hline ISTJ & 0.75 \\
\hline ENFP & 0.84 \\
\hline ENTP & 0.98 \\
\hline ESTJ & 0.94 \\
\hline ESFJ & 0.89 \\
\hline ENFJ & 0.86 \\
\hline ENTJ & 0.86 \\
\hline
\end{tabular}

Measurement of WLBA is, greater than 0.5 there is a work life balance, $0-0.5$ moderately work life balance and less than 0 work life imbalance. Base on those measurements people who have ISTP, ISFP, INTP, ESTP, ESFP, ISTJ, ENFP, ENTP, ESTJ, ESFJ, ENFJ, ENTJ personality have work life balance but people who have ISFJ, INFJ, INTJ, INFP personality have moderately balanced work life. According to the findings there are no WL imbalance respondents. And identify that, all who are pertaining to moderately balanced WL have introversion personality and majority of WLB respondents compromised with extroversion personality indicator. 
Table 5: Personality type and WLB factors

\begin{tabular}{|c|c|c|c|c|}
\hline & Work & Family & Social & Self \\
\hline \multirow{8}{*}{$\begin{array}{l}\text { Personality type which } \\
\text { have } \\
\text { High WLB factors }\end{array}$} & ESFJ & ENFJ & ESFJ & ENFJ \\
\hline & ENTJ & ESFJ & ESTJ & ESFJ \\
\hline & & ESTJ & ENTP & ESTJ \\
\hline & & ENTP & ENTJ & ENTP \\
\hline & & & & ENTJ \\
\hline & & & & ENFJ \\
\hline & & & & ISTJ \\
\hline & & & & ESFI \\
\hline \multirow{5}{*}{$\begin{array}{l}\text { Personality type which } \\
\text { have low WLB factors }\end{array}$} & ISFJ & ISFP & INFJ & ISFJ \\
\hline & & INTJ & INTJ & \\
\hline & & INFJ & ISFJ & \\
\hline & & ISFJ & & \\
\hline & & INTP & & \\
\hline
\end{tabular}

Measurement of average of WLB factors is, equal to 5.00 considered as high balance of work, family, social and self. And also average value is $1.00-2.00$ considered as low balance of work, family, social and self. According to table 3 people who have ESFJ and ENTJ personality type have high work balance. But people who have ISFJ have low work balance. People who have ENFJ, ESFJ, ESTJ, and ENTP have high family balance. But people who have ISFP, INTJ, 
INFJ, ISFJ, INTP have low family balance. People who have ESFJ, ESTJ, ENTP, ENTJ have high social balance and people who have ENFJ, ESFJ, ESTJ, ENTP, ENTJ, ENFJ, ISTJ,ESFI have high self balance. But people who have INFJ, INTJ, ISFJ have low social balance and people who have ISFJ have low self - balance.

\section{Table 6: Anova table}

\begin{tabular}{|l|l|l|l|l|l|}
\hline & $\begin{array}{l}\text { Sum of } \\
\text { Squares }\end{array}$ & df & $\begin{array}{l}\text { Mean } \\
\text { Square }\end{array}$ & F & Sig. \\
\hline $\begin{array}{l}\text { Between } \\
\text { Groups }\end{array}$ & 3466.204 & 23 & 150.705 & 48.066 & .000 \\
\hline $\begin{array}{l}\text { Within } \\
\text { Groups }\end{array}$ & 395.056 & 126 & 3.135 & & \\
\hline Total & 3861.260 & 149 & & & \\
\hline
\end{tabular}

According to above table, significant value is .000 which less than 0.05 (< 0.05$)$. Therefore personality type is significant variable in WLB.

\section{Findings}

This study contributes to this research by providing additional empirical support to the opinion that the relationship of personality type on WLB. The findings also highlight that the relationship of personality type on WLB. 
According to the survey data most people have judging personality indicator and least people have perception personality indicator. And revealed that most people have the personality type of INTP, ISTJ, ESTJ, ESF, ENFJ and least people have the personality type of INTJ, ISTP, ESTP, ESFP, ENFP and ENTP. Moderate people have the personality type of the ISFJ, INFJ, ISFP and ENTJ.

According to the survey data people who have ISTP, ISFP, INTP, ESTP, ESFP, ISTJ, ENFP, ENTP, ESTJ, ESFJ, ENFJ, ENTJ personality have WLB. People who have ISFJ, INFJ, INTJ, INFP personality have moderately balanced WL. According to the findings there are no WL imbalance respondents.

People who have ESFJ and ENTJ personality type have high work balance. But people who have ISFJ have low work balance. People who have ENFJ, ESFJ, ESTJ, and ENTP have high family balance. But people who have ISFP, INTJ, INFJ, ISFJ, INTP have low family balance. People who have ESFJ, ESTJ, ENTP, ENTJ have high social balance and people who have ENFJ, ESFJ, ESTJ, ENTP, ENTJ, ENFJ, ISTJ,ESFI have high self- balance. But people who have INFJ, INTJ, ISFJ have low social balance and people who have ISFJ have low selfbalance.

Finally 0.000 of significant value indicates personality type is significant variable in WLB. 


\section{Conclusion}

The current study focuses on the testing the relationship of type of personality on WLB of academic staff of University of Kelaniya. Researchers used Myers-Briggs Type Indicator (MBTI) to assess the type of personality. There are sixteen types of personalities; ISTJ, ISFJ, INFJ, INTJ, ISTP, ISFP, INFP, INTP, ESTP, ESFP, ENFP, ENTP, ESTJ, ESFJ, ENFJ and ENTJ.

There are many factors which are influencing the WLB, however and individual's personality also plays a vital role in balancing the work life. It is easy to be realized that the personality of an individual can have effects on his/her own balance between work and family (Devadoss A.V, 2013).

The primary objective of this research is to examine the relationship of personality type of academic staff in University of Kelaniya with their WLB. And research proved that there is a relationship between personality type and WLB of academic staff in University of Kelaniya.

\section{Recommendations}

Research findings showed most of the respondents has Judging indicator and least amount has Perception indicator. According to the (LLC., 2012-2014) research E,N,F,J indicators indicated for Teacher career. Therefore recommend to enhance Extraversion, Intuition and Feeling indicators to execute the responders' career effectively. 
According to the research findings most of the responders has INTP, ISTJ, ESTJ, ESFJ and ENFJ personality type. But (LLC., 2012-2014) elaborated INTP -Architect, ISTJ - The inspector, ESTJ - The supervisor, ESFJ - The provider and ENFJ - Teacher. Rather enhancing Architect career indicators (INTP) it is better to enhance ENTP which emphasized Visionary career (LLC., 2012-2014) and its well match with the teacher career.

Based on the findings of WLB ENFJ type which match to the teacher career has balanced WL. One career showed less balanced WL which highly match with the teacher qualifications, that is INTJ- The mastermind, but other matching careers showed that responders has balanced WL for personality types such as ISTJ- The inspector, ENTP- Visionary, ESFP - The performer and ESFJ - The provider. Therefore recommend to INTJ personality responders to attempt to change $\mathrm{N}$ indicator to become $\mathrm{S}$. That means it is must to enhance sensing abilities to balance WL.

This research confined to find personality type of academic staff of University of Kelaniya, and level of WLB of each personality type and if there significant impact in personality type on WLB. But we can enhance the scope of the research, to find WLB of academic staff with each personality type but respond to gender differentiation, marital status differences. 
Kelaniya Journal of Human Resource Management

Volume 8 Number 1 January 2013

\section{References}

Argyris, C. (2008). Integrating the individual and the organization (Vol. 9th). Wiley.

Argyris, C. (October 1968). Industrial Relations. A Journal of Economy and Society, 1-117.

Blatt, G. (2002). Work/ Life balance; Wisdom or Whining. Organizational Dynamics, 31, No 2, 177 - 233.

Briggs, I. B. (1980, 1995). Gifts Differing: Understanding Personality Type (Vols. ISBN 0-89106-074-X). Mountain View, CA: Davies-Black.

Clark, E. A. (2003). Behavioural and Cognitive Psychotherapy (Vol. $31)$.

D. Guest, M. J. (2003). A UK study of the relationship between human resource management and corporate performance. British Journal of Industrial Relations, 41, 2, 291-314.

Devadoss A.V, J. M. (2013, October). A Study of Personality Influence in Building Work Life Balance Using Fuzzy Relation Mapping (FRM). A Study of Personality Influence in Building Work Life Balance Using Fuzzy Relation Mapping (FRM). The International Journal of Data Mining Techniques and Applications (IJDMTA), 02, 211-216.

Haché. L, D. R. (2002). Memramcook, NB: national Life/Work Centre.

Hudson. (2005). he Case for Work/Life Balance: Closing the Gap Between Policy and Practice. 
Jung, C. (1971). Theory of psychological types.

LLC., T. P. (2012-2014).

Myers, I. B. ( 1980, 1995). Gifts Differing: Understanding Personality Type. Mountain View. Davies-Black Publishing ISBN 089106-074-X.

Pearman, R. R., \& Albritton, S. C. (1997). I'm Not Crazy, I'm Just Not You (First ed.). Palo Alto. California: Davies-Black Publishing ISBN 0-89106-096-0.

S.Susi, K. J. (2001). Work-Life Balance: The key driver of employee engagement. Asian Journal of Management (Vol. 02).

Sekaran, U. ( 2006). Research Methods For Business: A Skill Building Approach (Vol. 4th). Wiley India Pvt. Limited.

Tieger, P. D., \& Barron-Tieger, B. (n.d.). The Art of SpeedReading People. New York. Brown and Company ISBN 978-0-31684518-2.

Zeisset, C. (2006). The Art of Dialogue: Exploring Personality Differences for More Effective Communication . Gainesville: Center for Applications of. 